\title{
Farklı yanlılık düzeltme yöntemlerinin istatistiksel ölçeğe indirgenmiş yağış projeksiyonlarına uygulanmasi
}

\author{
Umut KIRDEMIR* ${ }^{*}$ Umut OKKAN \\ Balıkesir Üniversitesi, Mühendislik Fakültesi, Inşaat Mühendisliği Bölümü, Çă̆ış Yerleşkesi, Balıkesir \\ Geliş Tarihi (Received Date): 31.10 .2019 \\ Kabul Tarihi (Accepted Date): 27.11.2019
}

\section{Özet}

İstatistiksel ölçek indirgeme modelleri kaba çözünürlüklü iklim modellerinin yerel ölçeğe indirgenmesinde oldukça etkili araçlar olup, iklim değişikliği çalışmalarında sıklıkla yararlanılmaktadır. Çeşitli hidro-meteorolojik değişkenlerin projeksiyonlarında kullanılan farklı iklim modelleri kendi bünyesinde barındırdıkları yanlılık sebebiyle ölçek indirgeme modellerinin performanslarını etkilemekte ve tahminlere ait hassasiyeti azaltabilmektedir. Bu nedenle, ölçek indirgeme modellerinin yanında yanlılık düzeltme işlemlerine de ihtiyaç duyulmaktadır. Bu çalışmada, Hükümetlerarası İklim Değişikliği Paneli'ne (IPCC) ait 5. Değerlendirme Raporu'na göre farkl emisyon senaryolar çerçevesinde hazırlanmış iklim modelleri ve farklı yanlılık düzeltme yöntemleri ile Gediz Havzası'na ait yağış projeksiyonları elde edilmiş ve bunu takiben farkl yanlılık düzeltme yöntemlerinin yă̆ış tahminlerine olan etkileri araştırllmıştır. Bunun için öncelikle, Gediz Havzası yağışlarını temsil eden tahminleyici seçimi yapılmış, daha sonra ilgili yă̆ış tahminleyicileri ile kaba çözünürlüklü iklim modelleri istasyon ölçeğine indirgenmiştir. Çalışmada 2015-2050 gelecek dönemine ait kaba çıktıları bulunan 12 adet farkl küresel iklim modelinden faydalanılmış ve bu iklim modellerinden türetilen projeksiyonlar birleştirilerek daha kuvvetli tahminler elde edilmesi amaçlanmıştır. Çoklu iklim modellerinin birleşiminden sonra tahminlerde var olan yanlılıklar Kantil Haritalama (QM), Eş Oran Kantil Haritalama (ERQM), Trendsizleştirilmiş Kantil Haritalama (DQM) ve Kantil Delta Haritalama (QDM) yöntemleri ile ayrı ayr düzeltilmiştir. Tüm performans indislerini kapsayan bulgulara göre, QM yönteminin en büyük hata değerlerini veren yaklaşım olduğu görülmüştür. Diğer yandan, QDM yöntemininise rölatif değişimleri diğer yöntemlere göre daha iyi yansitabildiği sonucuna varılmıştır. Ekstrem süreçleri temsil eden performans indisleri incelendiğinde de, QDM'nin ortalama tabanl yă̆ıs projeksiyonlarının değerlendirilmesinde daha üstün olduğu gözlenmiştir.

Anahtar kelimeler:Yanlılık düzeltme, ölçek indirgeme, iklim modelleri, Gediz Havzası.

\footnotetext{
*Umut KIRDEMIR, umut.kirdemir@gmail.com, https://orcid.org/0000-0001-5336-4842

Umut OKKAN, umutokkan@balikesir.edu.tr, https://orcid.org/0000-0003-1284-3825
} 


\title{
Implementation of different bias correction methods to statistically downscaled precipitation projections
}

\begin{abstract}
Statistical downscaling models are very effective tools for downscaling coarseresolution climate models to local scale and are widely used in climate change studies. The different climate models used in the projections of various hydro-meteorological variables affect the performance of the downscaling models due to their inherent bias and can reduce the precision of predictions. Due to this reason, bias correction methods are needed in addition to the downscaling models. In the study prepared, the precipitation projections were obtained by the climate models derived within the framework of different emission scenarios in terms of the 5th Assessment Report of Intergovernmental Panel on Climate Change (IPCC) and the effects of different bias correction methods on precipitation estimations were investigated as well. For this purpose, firstly, the predictor selection which represents the precipitation of Gediz Basin was carried out and then the coarse-resolution climate models were downscaled to station scale by means of the related precipitation predictors. In the study, 12 different global climate models having raw outputs of 2015-2050 future period were utilized and it was aimed to obtain stronger predictions by combining the projections which were derived by these climate models. Subsequent to combination of multi-model projections, the bias existing in predictions were corrected by Quantile Mapping (QM), Equiratio Quantile Mapping (ERQM), Detrended Quantile Mapping (DQM) and Quantile Delta Mapping (QDM), respectively. According to the obtained results including all performance measures, it has been deduced that QM offers the largest error values. On the other side, it has been concluded that QDM method can better reflect relative changes compared to other methods. When performance indices pointing out extreme processes were also investigated, it was observed that QDM was superior in the evaluation of mean-based precipitation projections.
\end{abstract}

Keywords:Bias correction, downscaling, climate models, Gediz Basin.

\section{Giriş}

Küresel 1sınmayla birlikte meydana gelen ani iklimsel değişimler ülkemizde ve dünyada hidrolojik açıdan birtakım değişimler meydana getirmekte ve bu durum yüzey sularının kontrolü ve su kaynaklarının yönetimi konusunda geleceğe yönelik araştırmalar yapma ihtiyacı doğurmaktadır. Dünya genelinde istatistiksel açıdan anlamlı seviyede artan sıcaklıklar dünya üzerinde evapotranspirasyon miktarının artışına, bu da içme, kullanma veya tarımsal sulama için kullanılan yüzey sularının atmosferik zorlamalar sebebiyle azalmasına sebep olmaktadır [1]. Bu hususta, küresel dolaşım modelleri (GCM) adı verilen araçlar dünya iklimini matematiksel olarak modellemek için kullanılmakta ve iklim değişikliğinin su kaynaklarına etkisini araştırmak için de faydalanılmaktadır $[2,3,4]$. Mekânsal olarak farklı çözünürlüklerde hazırlanan bu modeller geçmiş ve gelecek döneme ait atmosferik ve oşinografik iklimsel tahminler barındırmaktadır. Kaba çözünürlükte hazırlanan bu modeller her ne kadar farklı iklimsel değişkenleri modelleyebilme becerisi gösterse de kendi içlerinde bir miktar yanlılıklar barındırmaktadır. $\mathrm{Bu}$ yanlılıklar genel olarak iklim modellerinin antropojenik 
zorlamaları, hava olaylarındaki içsel değişkenliği ve bu değişkenliğe sebep olan bazı pozitif ve negatif geri beslemeleri veya incelenen bölgenin topografik yapısının etkilerini tam olarak modelleyememesinden kaynaklanabilmektedir. İklim değişikliği çalışmalarında kullanılan GCM'lerin mekânsal çözünürlükleri yansıtmada yetersiz oluşu ve bazı atmosferik süreçleri modellemede sınırlı yeteneklere sahip olması sebebiyle, bu modellerin bir miktar yanlılık barındırdıkları bilinmektedir $[1,5]$. Bu sebeplerden dolay1, daha güvenilir tahminler elde edebilmek adına bahsi geçen sistematik hatalar 'yanlılık düzeltme' yöntemleri ile azaltılabilmektedir. Yanlılık düzeltme yöntemlerinin sistematik hataları düzeltmede kullanışlı bir araç oluşu bu yöntemlerin iklim değişikliği çalışmalarının vazgeçilmez bir parçası haline getirmiştir. $\mathrm{Bu}$ yöntemler incelenen değişkene ait verilerin çeşitli dağılım momentlerine uygulanmakla birlikte [6-9], değişkenin uyum gösterdiği dağılım yapısı da esas alınarak yapılmaktadır [10, 11]. Literatürde, bu yöntemleri kıyaslayan bazı çalışmalar yer almakta ve bu çalışmalardan elde edilen bulgulara göre dağılım tabanlı yanlılık düzeltme yöntemlerinin diğer yöntemlere göre daha uygun sonuçlar türettiği sonucuna varılmaktadır [12, 13]. Örneğin, Chen vd. [14] tarafından yapılan çalışmada, gözlenmiş ve GCM verilerinin ortalamalarını ve dağılımlarını esas alan 6 adet yanlılık düzeltme yönteminin hidrolojik model performansına olan etkileri araştırılmıştır. Söz konusu çalışmadaki bulgulara göre, dağılım tabanlı metotların yağış simülasyonlarını hidrolojik model performansını arttıracak şekilde düzelttiği sonucuna varmışlardır. Fangvd.[15] tarafından yapılan çalışmada ise yağış, sıcaklık ve akım simülasyonlarına ait yanlılıklar farklı düzeltme yöntemleri ile değerlendirilmiştir. Çalışmalarında farklı performans indisleri dikkate alınarak simülasyonların değişkenlik ölçütlerini ve dağılımlarını hesaba katan yöntemlerin yağış ve akım yanlılıklarını daha iyi düzeltebildikleri sonucuna varmışlar, sıcaklık değişkeni için ise çalışmada kullanılan tüm yöntemlerin uygun ve benzerperformans sergilediğini tespit etmişlerdir.

Dağılım tabanlı yanlılık düzeltme yöntemleri literatürde olasılık haritalama [17], kantil haritalama [18], histogram eşitleme [19], dağılım haritalama [12] gibi isimlerle bahsedilmiş (bu çalışmada kantil haritalama olarak isimlendirilecektir) ve bu yöntemler genel olarak GCM dağılımlarının gözlenmiş dağılımların üzerine haritalanması esasına dayanmaktadır. Hempel vd.[16] tarafından gerçekleştirilen çalışmaya göre, iklimsel hassasiyetin modellerde yansitabilmesi için GCM projeksiyonlarındaki rölatif değişimlerin yanlılıkları düzeltilmiş projeksiyonlardaki rölatif değişimlerle uyum içinde olması gerektiği savunulmaktadır. Bununla birlikte kantil haritalama işlemi ile düzeltilmiş tahminler kimi zaman simülasyon değerlerini gereğinden fazla olarak tahminleyebildiği yani bahsi geçen rölatif trendleri koruyamadığı bulgularına da rastlanmıştır [20]. Yukarıda belirtilen bilgiler ışı̆̆ında hazırlanan bu çalışmada, kantil haritalama esasına dayalı farklı yanlılık düzeltme yöntemlerinin performansları araştırılmıştır. Çalışma, Gediz Havzası yağışları üzerinde uygulanmıştır. Çalışmada öncelikle 12 adet GCM, iki adet istatistiksel ölçek indirgeme metodu ile istasyon ölçeğine indirgenmiş daha sonra çoklu model sonuçları Bayesçi yaklaşımla birleştirilerek tekil model sonuçları elde edilmiştir. Elde edilen tahminlerdeki sistematik hatalar 4 adet farklı yanlılık düzeltme yöntemi ile düzeltilmiş ve 9 adet farklı performans indisi ile incelenerek yanlılık düzeltme yöntemlerinin performansları belirlenmiştir.

Çalışmada bahsi geçen çalışma alanı ve kullanılan veriler Bölüm 2'de, kullanılan yöntemler Bölüm 3'te, elde edilen bulgular Bölüm 4'te ve bulgulara ait sonuçlar Bölüm 5 'te detaylı olarak verilmiştir. 


\section{2. Çalışma alanı ve kullanılan veriler}

Bu çalışmada, kullanılan yanlılık düzeltme yöntemleri Ege Bölgesi'nde bulunan ve yaklaşık $17.125 \mathrm{~km}^{2}$ drenaj alanına sahip Gediz Havzası'nın aylık toplam yağışlarına uygulanmıştır. Akdeniz ikliminin hüküm sürdügü Gediz Havzası'nda su kaynaklarının büyük bir bölümü sulama için kullanılmakta ve havzada yaklaşık olarak 110000 ha'lık tarımsal sulama alanı bulunmaktadır. Çalışmada kullanılan ve havzada gözlenen yağış verileri Meteoroloji Genel Müdürlüğü ve Devlet Su İşleri Genel Müdürlüğü tarafından işletilen 39 adet meteoroloji istasyonundan elde edilmiştir. İlgili yağış istasyonlarının 20 tanesi ayrıca sıcaklık gözlemi de yapmaktadır. İklim modellerinde ortak referans geçmiş senaryo dönemi olan Ocak 1980-Aralık 2005 dönemini temsil eden verilere göre, havzada yıllık toplam yağış yaklaşık olarak $550 \mathrm{~mm}$ ve yıllık ortalama sıcaklık yaklaşık olarak $15^{\circ} \mathrm{C}$ civarındadır.

İstatistiksel ölçek indirgeme çalışmalarında yararlanılmak üzere Avrupa Orta Vadeli Hava Tahminleri Merkezi (ECMWF) tarafindan servis edilen $0,75^{\circ} \times 0,75^{\circ}$ alan çözünürlüğüne sahip ERA-Interim reanaliz veri setleri kullanılmıştır. Farklı atmosferik seviyelerdeki (200 hPa, $500 \mathrm{hPa}, 850 \mathrm{hPa}$ ) geopotansiyel yükseklik, sıcaklık, rölatif nem ve deniz seviyesideki basınç, yüzeydeki sıcaklık, basınç ve yağış gibi 12 adet değişkene ait verileri barındıran reanaliz verilerinin temsil ettiği periyot kullanılan meteoroloji istasyonları ile paralellik göstermektedir. Tahminleyici seçiminde kullanılan süreç için Okkan ve Kirdemir [3] çalışması incelenebilir. Ayrıca çalışmada IPCC'nin 5. Değerlendirme Raporu'nda değinilen iklim senaryolarından faydalanılmıştır. Sera gazı emisyonlarının zamana göre değişimini dikkate alınarak türetilen temsili konsantrasyon rotaları (RCP) senaryolarından RCP8.5 senaryosu çalışma kapsamında kullanılmıştır. RCP8.5 senaryosuna göre 2100 yılında atmosferdeki CO2 derişiminin yaklaşık olarak $1370 \mathrm{ppm}$ 'den fazla olması ve radyatif zorlamanın yaklaşık $8.5 \mathrm{~W} / \mathrm{m}^{2}$ civarından olması beklenmektedir. Ayrıca RCP8.5 senaryosu diğer RCP senaryoları arasında kötümser senaryo olarak da anılmaktadır. Çalışmada kaba çözünürlüklü referans dönem (REF) ve gelecek dönem RCP8.5 iklim senaryosu sonuçlarına sahip 12 adet GCM'den faydalanılmıştır. Nispeten daha iyimser senaryolar olan RCP4.5 ve RCP2.6 ise yöntemsel karışıklık yaratmamak adına çalışma kapsamına alınmamıştır. Kullanılan GCM'lerin barındırdıkları iklimsel değişkenler reanaliz veri setinde kullanılan değişkenler ile uyum göstermektedir. Kullanılan GCM'lerde REF'e ait tahminler meteoroloji ve reanaliz veri setindeki zaman periyodu ile aynı dönemi temsil etmekte, RCP8.5 senaryosuna ait veriler ise Ocak 2015-Aralık 2050 dönemine aittir. Şekil 1'de çalışmada kullanılan meteoroloji istasyonlarının havza üzerindeki konumları ve havzayı kapsayan ERA-İnterim ızgaraları verilmiştir. Havzada bulunan meteoroloji istasyonların konum bilgileri, hangi kurum tarafından işletildiği ve çalışmada kullanılan GCM'lere ait detaylı bilgiler Okkan ve Kirdemir [3] çalışmasında detaylı olarak verilmiştir.

\section{Yöntem}

\section{1. Ölçek indirgeme ve çoklu model birleştirme stratejisi}

Çözünürlük bakımından nispeten kaba olan genel dolaşım modelleri (GCM'ler) iklim değişikliğinin yerel ölçekteki hidro-meteorolojik etkilerini değerlendirmede yeterli değildir. $\mathrm{Bu}$ nedenle, istasyon ölçeğinde kaba çözünürlüklü atmosferik modellerin etkisini yorumlamak için yüksek çözünürlüklü sonuçlara ihtiyaç duyulmaktadır $[21,22$, 23]. Bu ihtiyaçtan dolayı kaba çözünürlüklü GCM verilerinin ölçek indirgeme yöntemi 
kullanılarak yerel ölçeğe indirgenmesiyle çalışma alanın iklimsel özelliklerini daha güvenilir bir şekilde temsil eden veri setine ulaşmak mümkündür.

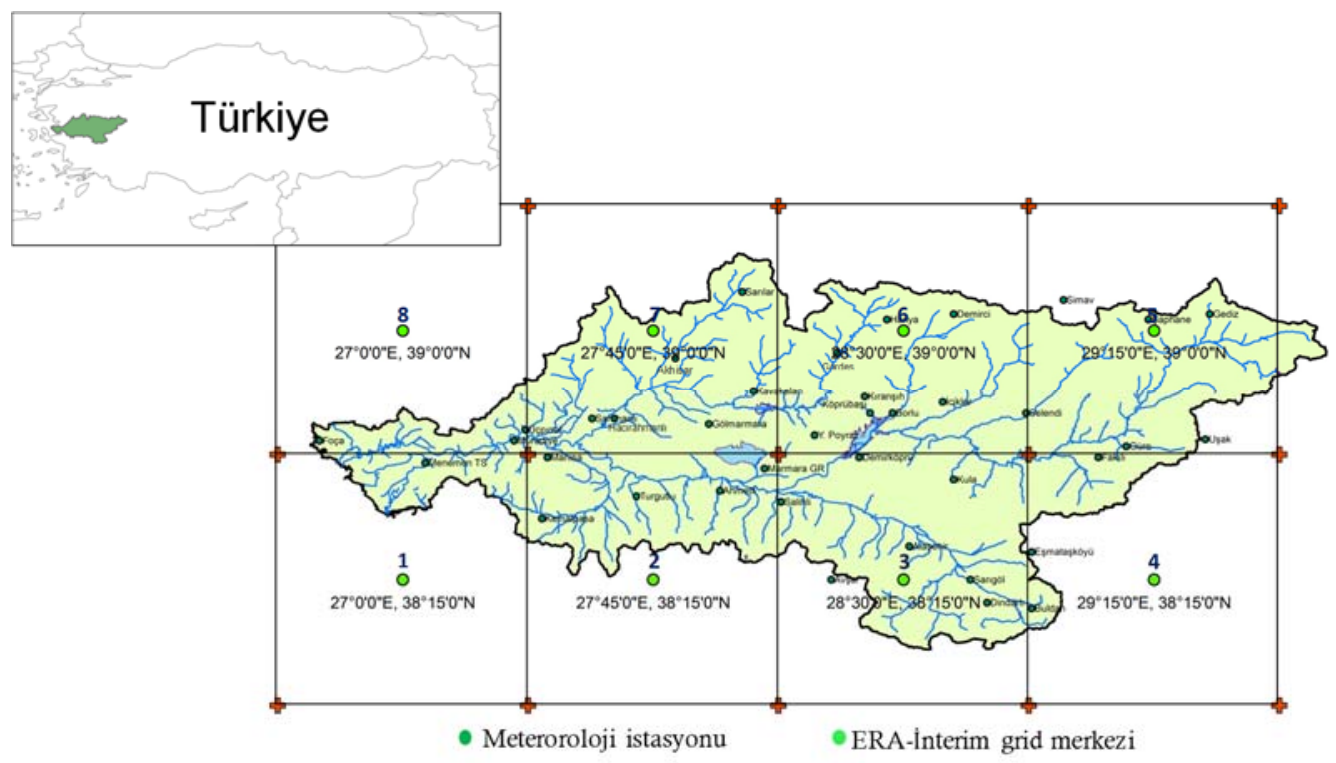

Şekil 1. Gediz Havzası'nda bulunan meteoroloji istasyonları ve havzayı kapsayan ERAInterim 1zgaraları $[3,4]$.

Ölçek indirgeme modelleri genel olarak istatistiksel ve dinamik olarak iki gruba ayrılmaktadır. Dinamik ölçek indirgeme bölgesel iklim modellerine ait çalışmaları içermekte ve yüksek çözünürlükte bilgi barındırmaktadır. Ancak bu modeller çok fazla girdi istemekte, fazla parametre içermekte ve başlangıç-sınır koşulları olarak GCM'lerin kaba çıktılarını kullanmaktadırlar. GCM'lerden gelen belirsizlikler bu modellerde yanlılık miktarını arttırmakta bununla beraber uygulama aşamasında işlem yükü de oldukça fazladır. Bu nedenle, kaba ölçekli tahminleyiciler ile yerel ölçekli gözlenmiş değişkenler arasında istatistiksel ilişkilerin kurulmasına dayanan istatistiksel ölçek indirgeme modelleri daha pratik yöntemler olarak anılmaktadır [3, 21-23]. Bu çalışmaya altlık teşkil eden Okkan ve Kirdemir[3] çalışmasında, makine öğrenmesi teorisine dayanan yapay sinir ağları (YSA) ve en küçük kareler destek vektör makinesi (EKDVM) yöntemleri 39 adet istasyonun yağış ölçek indirgenmesinde kullanılmıştır.Söz konusu çalışmada, öncelikle tüm olası regresyonlar (APREG) yöntemi ile Gediz Havzası yağışlarını temsil eden tahminleyici değişkenler tespit edilmiştir. APREG yönteminde oluşturulan lineer regresyon modellerinde girdi olarak ERA-Interim veri setleri kullanılmış ve ilgili istasyon yağışları tahmin edilmeye çalışılmıştır. Bu uygulamada işlem yükünü azaltan ve aynı zamanda en uygun tahmini veren tek değişkenli bir model dikkate alınmış ve bu modelde ERA-Interimr eanaliz veri setine ait yağış $(p r)$ değişkeni en uygun tahminleyici olarak seçilmiştir. Böylece, her bir istasyon için, istatistiksel ölçek indirgeme modellerinde kullanılmak üzere modele girdi olarak sunulacak değişken seçilmiş ve yerel ölçekteki yağışlar arasında ilişki kuracak model parametreleri tahmin edilmeye çalışılmıştır [3]. İstatistiksel ölçek indirgeme uygulamalarında YSA ve EKDVM modellerinin performanslarını değerlendirmede kullanılan indisler Moriasi vd.[24] çalışmasında detaylı bir şekilde verilmiştir.

Literatürde tekil iklim modellerinin yarattığı belirsizliklerden, ayrıca çoklu iklim modellerinin uygulamalarında hangi modelin bir diğerine göre üstün olduğunun 
belirsizliği vurgulanmıştır [4, 21].Bu bağlamda Knutti vd. [25] tarafından hazırlanan çalışmada, IPCC'in 4. Değerlendirme Raporu sonrası çoklu iklim projeksiyonlarının birleştirilmesi hakkında tavsiyelerde bulunulmuştur. Hazırlanan raporda çalışmacılar model sonuçlarının ağırlıklı ortalamalarının kullanımını tavsiye etmişler, bu nedenle çalışmada Bayes Model Ortalaması (BMA) yöntemi kullanılarak 12 modele ait indirgenmiş sonuçların ağırlıklı ortalaması alınmıştır. Böylece REF ve RCP8.5 senaryosu kapsamında her bir istasyon için indirgenmiş ve akabinde ağırlıklandırılmış yağış tahminleri elde edilmiştir. BMA yönteminin detaylı anlatımı Okkan ve Kirdemir[4] çalışmasında verilmiştir.

\section{2. Çalışmada kullanılan yanlılık düzeltme yöntemleri}

\subsubsection{Kantil haritalama}

Kantil haritalama (QM) yanlılık düzeltme yöntemi GCM'lere ait dağglımların gözlenmiş verilere ait dağılımların üzerine haritalanması esasına dayanmaktadır. $\mathrm{Bu}$ yöntemde, verilerin uyum gösterdiği teorik dağılımlar dikkate alınarak REF dağılımları altında her aya ait geçmiş ve gelecek dönem eklenik olasılık değerleri ve bu değerlere karşılık gelen kantil değerleri gözlenmiş dağılımlar altında elde edilerek düzeltilmiş yağış projeksiyonları elde edilir. QM ile elde edilen düzeltilmiş yağış değeri aşağıdaki formül ile elde edilebilir $[3,13]$.

$$
y_{\text {cor }}(t)=F^{-1}\left(F\left(y_{\text {mod }}(t), \theta_{R E F}\right), \theta_{o b s}\right)
$$

Burada, $y_{\text {cor }}(t) \mathrm{t}$ zamanındaki düzeltilmiş yağış değerini, $y_{\text {mod }}(t) \mathrm{t}$ ayındaki birleştirilen iklim modelinden elde edilen REF veya RCP8.5 senaryosuna ait yağış değerini, $\theta_{R E F}$ ve $\theta_{\text {obs }}$ sırasıyla benzeştirilen REF ve gözlenmiş verilerden elde edilmiş dağılım parametrelerini, $F($.$) ve F^{-1}($.) ise sırasıyla REF dağ $11 ı$ ına ait eklenik olasılık fonksiyonunu (CDF) ve gözlenmiş verilere ait ters kümülatif olasılık fonksiyonunu temsil etmektedirler.

\subsubsection{Eş oran kantil haritalama}

Wang vd.[26] tarafınca yürütülen çalışmada, eş uzaklık kantil haritalama yönteminin [27] oran ölçme düzeyindeki değişkenlerin yanlılıklarını düzeltmede yetersiz kalmasından dolayı eş oran kantil haritalama (ERQM) yöntemi geliştirilmiştir ve bu yöntemde standart QM yöntemine ek olarak gelecek döneme ait dağılım yapısı da dikkate alınmıştır. Bu yöntem ile düzeltilmiş yağış değeri aşağıda verilen Denklem 2 aracılığıyla elde edilebilir.

$y_{\text {cor }}(t)=y_{\text {mod }}(t) \frac{F^{-1}\left(F\left(y_{\text {mod }}(t), \theta_{\text {mod }}\right), \theta_{o b s}\right)}{F^{-1}\left(F\left(y_{\text {mod }}(t), \theta_{\text {mod }}\right), \theta_{R E F}\right)}$

Burada, $\theta_{\text {mod }}$ modellenmiş geçmiş veya gelecek döneme ait verinin dağılım parametrelerini temsil etmektedir.

\subsubsection{Trendsizleştirilmiş kantil haritalama}

Cannon vd. [13] tarafından yapılan çalışma, QM veya ERQM uygulamalarında geçmiş verilerin dağılım yapısı esas alınarak değerlendirilen tahminlerin tanımlı aralıklarını aşması durumunda ekstrapolasyon önermemektedir. Bunun yerine, REF dağılımı 
içerisindeki eğilim yapısı elimine edildikten sonra, tekrar ilgili rölatif eğilim miktarını düzeltilmiş değere etki ettirme ilgili çalışmada daha tutarlı görülmüştür. DQM olarak kısaltılan yöntemdeki süreç aşağıdaki gibi işletilmektedir.

$y_{\text {cor }}(t)=F^{-1}\left(F\left(\frac{\bar{y}_{R E F}(t) y_{\text {mod }}(t)}{\bar{y}_{\text {mod }}(t)}, \theta_{R E F}\right), \theta_{o b s}\right) \frac{\bar{y}_{\text {mod }}(t)}{\bar{y}_{R E F}(t)}$

Burada, $\overline{y_{R E F}}$ ve $\overline{y_{m o d}}$ sirasıyla $t$ ayındaki uzun dönem REF ve modellenmiş verilerin ortalamasinı ifade etmektedir.

\subsubsection{Kantil delta haritalama}

Kantil Delta Haritalama (QDM) metodu Cannon vd.[13] tarafindan önerilmiş ve doğrudan rölatif değişimler dikkate alınarak modellenmiş verilerdeki yanlılıkları düzeltilme yoluna gidilmiştir. Bu yöntem DQM ile benzerlikler gösterse de, aralarındaki en büyük fark DQM'de sadece ortalamalar arasındaki rölatif değişimleri dikkate alınırken, QDM'de bu durum tüm yüzdelik değerleri için uygulanmaktadır. QDM ile düzeltilmiş yağış değerleri Denklem 4'te verildiği şekilde hesaplanabilmektedir.

$$
y_{c o r}(t)=F^{-1}\left(F\left(y_{\text {mod }}(t), \theta_{\text {mod }}\right), \theta_{o b s}\right)\left(\frac{y_{\text {mod }}(t)}{F^{-1}\left(F\left(y_{\text {mod }}(t), \theta_{\text {mod }}\right), \theta_{R E F}\right)}\right)
$$

Çalışmada, kullanılan yanlılık düzeltme yöntemlerinin performanslarını değerlendirmek üzere 9 farklı indisten faydalanılmıştır. $\mathrm{Bu}$ indisler uzun dönem yağ 1 ş verilerine uygulanmış aritmetik ortalama (AO), sulak periyot ortalaması (SPO), kurak periyot ortalaması (KPO), kış, ilkbahar, yaz ve sonbahar mevsimlerine ait yağış ortalamaları (sırasıyla KO, İO, YO, SO), ekstrem yağışları temsil eden 95. yüzdelik değerlerini aşan yağışların toplamı (Y95) ve 99. yüzdelik değerlerini aşan yağışların toplamı (Y99) şeklindedir. Rölatif değişim kavramı RCP8.5 senaryo yağışlarına ait indis değerlerinin REF yağışlarına ait indis değerlerine oranı ile elde edilmektedir. Yukarıda belirtilen tüm bu indisler düzeltilmemiş ve düzeltilmiş yağışlara ayrı ayrı uygulanmış ve daha iyi performans gösteren yöntemin düzeltilmemiş yağışlardaki rölatif değişimleri daha iyi temsil edebildiği düşünülmüştür $[4,28]$

\section{Bulgular}

Çalışmada, yanlılık düzeltme yöntemlerinin kullanılmasından önce, kaba çözünürlüklü GCM simülasyonları YSA ve EKDVM yöntemlerine dayanan istatistiksel ölçek indirgeme yöntemleri ile istasyon ölçeğine indirgenmiştir. Reanaliz veri setinde bulunan yağış tahminleyicisi ölçek indirgeme yöntemlerine girdi olarak sunulmuş ve 39 adet meteoroloji istasyonu için kaba çözünürlüklü GCM simülasyonları istasyon ölçeğine indirgenmiştir. YSA ve EKDVM ile elde edilmiş her bir istasyona ait ölçek indirgeme sonuçları Okkan ve Kirdemir [3] çalışmasında verilmiştir. Söz konusu performanslara göre kullanılan her iki yöntem ile istasyonların yaklaşık \%90'ında 'çok iyi' ve 'iyi' performanslar sağlanmıştır. İlgili meteoroloji istasyonunda hangi modele ait sonuçların kullanıldığı bilgisi söz konusu kaynakta mevcuttur. Aynı çalışmada, her bir istasyon için hangi ölçek indirgeme modeline ait sonuçların kullanılacağına karar verildikten sonra, BMA yöntemi ile tahminler ağırlıklandırılmış ve belirsizliği azaltılmış projeksiyonların 
elde edildiği vurgulanmıştır.Bu çalışmada, Okkan ve Kirdemir [3] tarafından daha önceden elde edilen senaryo bazlı projeksiyonlar yanlılık düzeltme işlemlerine maruz bırakılmıştır.

Tablo 1. Manisa istasyonu için gözlenmiş (A), REF (B) ve RCP8.5 (C) senaryo yağışlarına ait PPCC testi sonuçları.

A.

\begin{tabular}{|c|c|c|c|c|c|c|c|c|c|c|c|c|}
\hline \multirow{3}{*}{ Aylar } & \multicolumn{12}{|c|}{ Teorik Dağııımlar } \\
\hline & \multicolumn{3}{|c|}{ Normal } & \multicolumn{3}{|c|}{ LN2 } & \multicolumn{3}{|c|}{ Gumbel } & \multicolumn{3}{|c|}{ Gamma-2 } \\
\hline & $\mu$ & $\sigma$ & $r\left(x_{m}, x_{m}{ }^{\prime}\right)$ & $\mu$ & $\sigma$ & $r\left(x_{m}, x_{m}{ }^{\prime}\right)$ & $\alpha$ & $\beta$ & $r\left(x_{m}, x_{m}{ }^{\prime}\right)$ & $\alpha$ & $\beta$ & $r\left(x_{m}, x_{m}{ }^{\prime}\right)$ \\
\hline Ocak & 113.208 & 86.435 & 0.970 & 4.500 & 0.678 & 0.953 & 0.014 & 73.785 & 0.979 & 65.993 & 1.715 & 0.975 \\
\hline Şubat & 94.477 & 72.252 & 0.941 & 4.318 & 0.679 & 0.994 & 0.017 & 61.523 & 0.988 & 55.255 & 1.710 & 0.994 \\
\hline Mart & 80.542 & 44.917 & 0.977 & 4.253 & 0.520 & 0.953 & 0.027 & 60.056 & 0.968 & 25.049 & 3.215 & 0.969 \\
\hline Nisan & 58.392 & 30.812 & 0.987 & 3.944 & 0.496 & 0.965 & 0.040 & 44.339 & 0.978 & 16.259 & 3.591 & 0.980 \\
\hline Mayıs & 34.254 & 30.743 & 0.929 & 3.238 & 0.769 & 0.985 & 0.040 & 20.232 & 0.978 & 27.592 & 1.241 & 0.987 \\
\hline Haziran & 9.785 & 15.871 & 0.782 & 1.636 & 1.136 & 0.962 & 0.078 & 2.546 & 0.882 & 25.743 & 0.380 & 0.965 \\
\hline Temmuz & 5.935 & 11.393 & 0.763 & 1.009 & 1.243 & 0.980 & 0.108 & 0.739 & 0.874 & 21.870 & 0.271 & 0.984 \\
\hline Ağustos & 4.577 & 10.166 & 0.710 & 0.631 & 1.334 & 0.984 & 0.121 & -0.059 & 0.833 & 22.578 & 0.203 & 0.979 \\
\hline Eylül & 11.173 & 21.213 & 0.759 & 1.650 & 1.236 & 0.982 & 0.058 & 1.498 & 0.871 & 40.273 & 0.277 & 0.983 \\
\hline Ekim & 31.489 & 30.786 & 0.933 & 3.114 & 0.819 & 0.980 & 0.040 & 17.447 & 0.981 & 30.098 & 1.046 & 0.992 \\
\hline Kasım & 101.223 & 57.320 & 0.966 & 4.478 & 0.527 & 0.965 & 0.021 & 75.079 & 0.974 & 32.459 & 3.118 & 0.971 \\
\hline Aralık & 142.546 & 87.883 & 0.926 & 4.799 & 0.568 & 0.985 & 0.014 & 102.463 & 0.976 & 54.182 & 2.631 & 0.978 \\
\hline Yıllık & 687.601 & 151.626 & 0.979 & 6.509 & 0.218 & 0.992 & 0.008 & 618.445 & 0.992 & 33.436 & 20.565 & 0.990 \\
\hline
\end{tabular}

B.

\begin{tabular}{|c|c|c|c|c|c|c|c|c|c|c|c|c|}
\hline \multirow{3}{*}{ Aylar } & \multicolumn{12}{|c|}{ Teorik Dağılımlar } \\
\hline & \multicolumn{3}{|c|}{ Normal } & \multicolumn{3}{|c|}{ LN2 } & \multicolumn{3}{|c|}{ Gumbel } & \multicolumn{3}{|c|}{ Gamma-2 } \\
\hline & $\mu$ & $\sigma$ & $r\left(x_{m}, x_{m}{ }^{\prime}\right)$ & $\mu$ & $\sigma$ & $r\left(x_{m}, x_{m}{ }^{\prime}\right)$ & $\alpha$ & $\beta$ & $r\left(x_{m}, x_{m}{ }^{\prime}\right)$ & $\alpha$ & $\beta$ & $r\left(x_{m}, x_{m}{ }^{\prime}\right)$ \\
\hline Ocak & 107.912 & 20.004 & 0.974 & 4.664 & 0.184 & 0.987 & 0.061 & 98.788 & 0.991 & 3.708 & 29.100 & 0.984 \\
\hline Şubat & 80.278 & 15.420 & 0.995 & 4.367 & 0.190 & 0.985 & 0.080 & 73.245 & 0.967 & 2.962 & 27.103 & 0.990 \\
\hline Mart & 70.425 & 16.881 & 0.958 & 4.227 & 0.236 & 0.971 & 0.073 & 62.726 & 0.967 & 4.046 & 17.405 & 0.970 \\
\hline Nisan & 48.065 & 9.981 & 0.984 & 3.851 & 0.205 & 0.967 & 0.123 & 43.513 & 0.942 & 2.073 & 23.189 & 0.974 \\
\hline Mayıs & 44.930 & 9.541 & 0.987 & 3.783 & 0.210 & 0.980 & 0.129 & 40.579 & 0.963 & 2.026 & 22.177 & 0.984 \\
\hline Haziran & 35.490 & 10.685 & 0.978 & 3.526 & 0.295 & 0.978 & 0.115 & 30.616 & 0.971 & 3.217 & 11.031 & 0.982 \\
\hline Temmuz & 14.951 & 5.612 & 0.990 & 2.639 & 0.363 & 0.961 & 0.219 & 12.391 & 0.961 & 2.106 & 7.099 & 0.975 \\
\hline Ağustos & 7.852 & 5.594 & 0.900 & 1.856 & 0.641 & 0.983 & 0.220 & 5.301 & 0.963 & 3.986 & 1.970 & 0.974 \\
\hline Eylül & 18.587 & 6.781 & 0.973 & 2.860 & 0.353 & 0.993 & 0.181 & 15.495 & 0.993 & 2.474 & 7.514 & 0.991 \\
\hline Ekim & 61.227 & 20.485 & 0.978 & 4.062 & 0.326 & 0.994 & 0.060 & 51.884 & 0.993 & 6.854 & 8.933 & 0.992 \\
\hline Kasım & 97.752 & 19.368 & 0.993 & 4.563 & 0.196 & 0.993 & 0.064 & 88.918 & 0.985 & 3.837 & 25.474 & 0.994 \\
\hline Aralık & 119.230 & 19.329 & 0.990 & 4.768 & 0.161 & 0.994 & 0.064 & 110.414 & 0.986 & 3.134 & 38.048 & 0.994 \\
\hline Yıllık & 706.700 & 53.564 & 0.982 & 6.558 & 0.076 & 0.981 & 0.023 & 682.269 & 0.958 & 4.060 & 174.069 & 0.981 \\
\hline
\end{tabular}

C.

\begin{tabular}{|c|c|c|c|c|c|c|c|c|c|c|c|c|}
\hline \multirow{3}{*}{ Aylar } & \multicolumn{12}{|c|}{ Teorik Dağılımlar } \\
\hline & \multicolumn{3}{|c|}{ Normal } & \multicolumn{3}{|c|}{ LN2 } & \multicolumn{3}{|c|}{ Gumbel } & \multicolumn{3}{|c|}{ Gamma-2 } \\
\hline & $\mu$ & $\sigma$ & $r\left(x_{m}, x_{m}\right)$ & $\mu$ & $\sigma$ & $r\left(x_{m}, x_{m}{ }^{\prime}\right)$ & $\alpha$ & $\beta$ & $r\left(x_{m}, x_{m}{ }^{\prime}\right)$ & $\alpha$ & $\beta$ & $r\left(x_{m}, x_{m}{ }^{\prime}\right)$ \\
\hline Ocak & 109.019 & 16.803 & 0.989 & 4.680 & 0.153 & 0.991 & 0.074 & 101.366 & 0.984 & 2.590 & 42.096 & 0.991 \\
\hline Şubat & 69.274 & 17.496 & 0.973 & 4.207 & 0.249 & 0.978 & 0.071 & 61.306 & 0.976 & 4.419 & 15.677 & 0.979 \\
\hline Mart & 65.157 & 14.373 & 0.967 & 4.153 & 0.218 & 0.975 & 0.086 & 58.611 & 0.974 & 3.170 & 20.552 & 0.974 \\
\hline Nisan & 49.108 & 9.967 & 0.987 & 3.874 & 0.201 & 0.992 & 0.124 & 44.568 & 0.988 & 2.023 & 24.275 & 0.992 \\
\hline Mayıs & 43.517 & 9.447 & 0.962 & 3.750 & 0.215 & 0.967 & 0.131 & 39.215 & 0.965 & 2.051 & 21.219 & 0.967 \\
\hline Haziran & 33.671 & 9.184 & 0.951 & 3.481 & 0.268 & 0.971 & 0.135 & 29.489 & 0.969 & 2.505 & 13.443 & 0.969 \\
\hline Temmuz & 14.557 & 5.956 & 0.987 & 2.601 & 0.393 & 0.978 & 0.208 & 11.844 & 0.980 & 2.437 & 5.974 & 0.987 \\
\hline Ağustos & 7.905 & 5.321 & 0.978 & 1.881 & 0.611 & 0.978 & 0.233 & 5.482 & 0.993 & 3.582 & 2.207 & 0.992 \\
\hline Eylül & 15.301 & 6.838 & 0.964 & 2.637 & 0.427 & 0.991 & 0.181 & 12.187 & 0.991 & 3.056 & 5.007 & 0.988 \\
\hline Ekim & 48.571 & 11.210 & 0.997 & 3.857 & 0.228 & 0.987 & 0.111 & 43.466 & 0.973 & 2.587 & 18.775 & 0.992 \\
\hline Kasım & 88.584 & 16.580 & 0.987 & 4.467 & 0.186 & 0.989 & 0.075 & 81.033 & 0.982 & 3.103 & 28.545 & 0.989 \\
\hline Aralık & 116.839 & 19.628 & 0.990 & 4.747 & 0.167 & 0.988 & 0.063 & 107.900 & 0.974 & 3.297 & 35.434 & 0.990 \\
\hline Yıllık & 661.503 & 53.707 & 0.993 & 6.491 & 0.081 & 0.991 & 0.023 & 637.043 & 0.965 & 4.360 & 151.705 & 0.992 \\
\hline
\end{tabular}

Çalışmada kullanılan yöntemler dağılım tabanlı stratejiler esas alınarak uygulandığından, düzeltilmemiş REF ve RCP8.5 senaryolarına ait projeksiyonlara ve gözlenmiş verilere ait dağglım uygunluk testleri uygulanmıştır. Bu hususta Normal, 2 parametreli Lognormal, Gumbel ve 2 parametreli Gamma dağılımları için olasılık çizgisi korelasyon katsayısı (PPCC) yöntemi uygulanmış, her bir istasyon için yapılan 
uyum testlerine göre tüm istasyonlarda verilerin 2 parametreli Gamma dağılımına daha yüksek korelasyon değerleri ile uyduğu tespit edilmiştir. Bu sebeple yanlılık düzeltme yöntemlerinde 2 parametreli Gamma dağılımına ait CDF ve ters CDF'ler kullanılmıştır. Tablo 1'de Manisa istasyonuna ait PPCC testi sonuçları örnek olarak verilmiştir (Burada kırmızı ile gölgelendirilmiş hücreler ilgili dağılıma ait kritik korelasyon katsayısı değerini aşan değerleri temsil etmektedir. $r\left(\mathrm{x}_{\mathrm{m}}, \mathrm{X}_{\mathrm{m}}\right)$ gerçek verilerle teorik dağılım altında elde edilen kantil değerleri arasındaki korelasyon katsayısını temsil etmektedir).

Uyum testlerinin ardından, çalışmada kullanılan yanlılık düzeltme yöntemlerinde kullanılacak dağılım parametreleri momentler yöntemiyle tahmin edilmiş ve daha sonra REF ve RCP8.5 senaryosuna ait yağış projeksiyonları düzeltilmiştir. Denklem 1-4'ten de anlaşılacağı üzere tüm yöntemlerde REF'e ait yağış düzeltmelerinde aynı değerler elde edilmektedir. Metotlar arasındaki fark gelecek dönem yağışlarını düzeltirken ortaya çıkmakta bu da aynı zamanda düzeltilmemiş projeksiyonlara ait rölatif değişimleri yansıtma konusunda çeşitli farklılıklara sebep olmaktadır. Gözlenen yağışlarla birlikte elde edilen düzeltilmemiş ve ilgili yöntemlerle düzeltilmiş projeksiyonlar incelendiğinde düzeltilmemiş yağış projeksiyonlarının gözlenmiş yağış değerlerine ait değişkenliği düşük tahmin ettiği gözlenmektedir. Bununla birlikte, düzeltilmemiş projeksiyonlar değişkenliklerde olduğu gibi çarpıklık değerlerini de düşük tahmin ettiği göze çarpmaktadır. Yanlılık düzeltme işlemleri ile REF'e ait dağılım momentleri gözlenmiş değerlere oldukça yakınsamakta ve fiziksel olarak mantıklı sonuçlar türetildiği sonucuna varılmaktadır (Şekil 2). Çalışmada kullanılan yöntemler gelecek döneme ait düzeltme işlemlerini farklı stratejilere göre yapmakta ve bu sebepten farklı yağış projeksiyonları oluşmaktadır. Tablo 2'de Akhisar istasyonu için RCP8.5 senaryosuna ait düzeltilmemiş ve ilgili yanlılık düzeltme yöntemleri ile elde edilmiş gelecek dönem yağışlarına ait bazı temel istatistikler verilmiştir. Tablo 2'den de görüldüğü üzere tüm yöntemler gelecek dönemde istatistiksel olarak farklı bir yapıya sahip olmakta aynı zamanda gelecekte ortalama yağışlarda birbirinden farklı azalmalar öngörmektedir.

Tablo 2. Akhisar istasyonu için düzeltilmemiş ve farklı yöntemlerle elde edilmiş gelecek dönem yağış projeksiyonlarına ait temel istatistikler

\begin{tabular}{ccccccccc}
\hline \multirow{2}{*}{ Yöntem } & \multicolumn{7}{c}{ Temel İstatistikler } \\
\cline { 2 - 8 } & Min $(\mathrm{mm})$ & Max $(\mathrm{mm})$ & Ortalama $(\mathrm{mm})$ & Medyan $(\mathrm{mm})$ & Standart Sapma $(\mathrm{mm})$ & Çarpıklik & Değişkenlik katsayıs1 & Değişim $(\%)$ \\
\hline Düzeltilmemiş & 0.39 & 124.10 & 43.11 & 39.12 & 28.18 & 0.51 & 0.65 & -6.04 \\
QM & 0.00 & 355.71 & 38.72 & 21.81 & 47.53 & 2.32 & 1.23 \\
ERQM & 0.00 & 326.36 & 42.57 & 27.72 & 49.98 & 2.17 & -16.25 \\
DQM & 0.00 & 369.47 & 43.80 & 28.89 & 50.89 & 2.23 & 1.17 & -7.93 \\
QDM & 0.00 & 346.30 & 43.62 & 28.28 & 50.53 & 2.11 & -16 & 1.16 \\
\hline
\end{tabular}

Özellikle düzeltilmemiş, ERQM, DQM ve QDM metotları ile düzeltilmiş aylık yağışlarda yaklaşık olarak \%5.3-\%8 arasında bir azalma öngörülürken, QM metodu kullanılarak elde edilen bu tahmin yaklaşı $\% 16.3$ civarındadır. Bu durumda Akhisar istasyonu için QM ile yapılan tahminler diğer yöntemler ile elde edilen tahminlere göre anlamlı bir farklılık yarattığı sonucuna varılabilir. Çalışmada kullanılan yanlılık düzeltme yöntemlerinin performansları daha önce belirtilen 9 farklı indis ile kıyaslanmıştır. $\mathrm{Bu}$ hususta düzeltilmiş ve düzeltilmemiş projeksiyonlardaki rölatif değişimlere ait mutlak hatalar incelenmiştir. Yapılan kıyaslamalarda QDM yönteminin AO indisine göre istasyonların anlamlı bir çoğunluğunda (yaklaşı \%82'sinde) diğer yöntemlere göre daha az hata ile rölatif değişimleri modellediği gözlenmiştir. QDM'in 
yanı sıra DQM yöntemi AO indisine göre Gördes, Köprübaşı, Demirköprü, Hanya, Sarılar ve Üçpınar, ERQM ise sadece Muradiye istasyonunda rölatif değişimleri diğer yöntemlere göre daha iyi yansıtabilmişlerdir. QM yöntemi ise AO indisine göre göreceli olarak daha yüksek hatalara sahip sonuçlar türettiği görülmektedir. AO indisindeki sonuçlara bakılacak olursa, QM'in tahmin ettiği aylık ortalama yağış değişimlerinde mutlak değerce yüksek tahmin etme olasılı̆̆ söz konusudur. Benzer durum, KPO, KO, İO, YO ve SO indislerinde de mevcuttur. QDM yanlılık düzeltme yöntemi bahsi geçen indislerde 39 adet meteoroloji istasyonunun birçoğunda düzeltilmemiş projeksiyonlardaki rölatif değişimleri diğer yöntemlere göre daha iyi yansıtabildiği gözlenmiştir. $\mathrm{Bu}$ indisler için yapılan hesaplamalarda yine AO'da olduğu DQM ve ERQM yöntemleri istasyonların bir kısmında daha küçük mutlak hata değerleri türettiği gözlenmiştir.

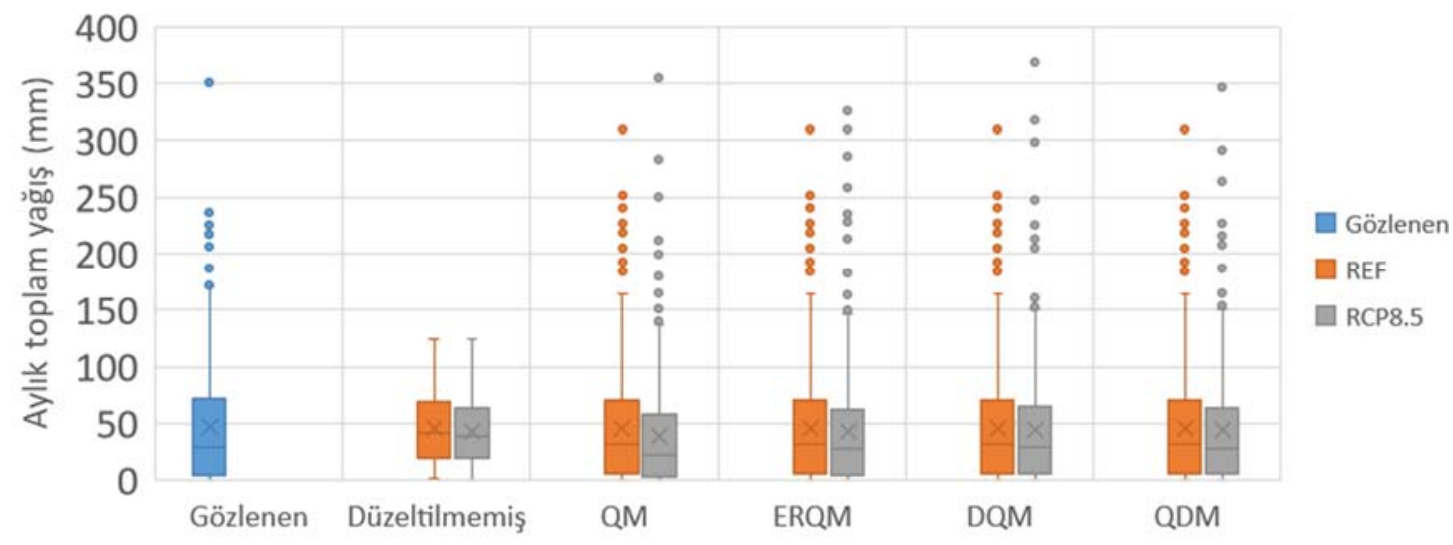

Şekil 2. Akhisar istasyonuna ait gözlenen aylık toplam yağışları, düzeltilmemiş ve her bir yanlılık düzeltme yöntemi ile elde edilmiş REF ve RCP8.5 senaryosuna ait aylık toplam yağışları temsil eden kutu diyagramları

$\mathrm{Bu}$ indisler için yapılan hesaplamalarda yine AO'da olduğu DQM ve ERQM yöntemleri istasyonların bir kısmında daha küçük mutlak hata değerleri türettiği gözlenmiştir. KPO indisinde ise yanlılık düzeltme yöntemlerinin performansları istasyonlara göre farklılık göstermektedir. $\mathrm{Bu}$ indise göre rölatif değişimlerin ERQM metodu ile 39 adet istasyonun 20'sinde diğer yöntemlere göre daha iyi modellenebildiği tespit edilmiştir. Yine bu istasyonların 15'inde QDM metodu KPO indisine ait rölatif değişimleri daha iyi yansıttığı görülmüştür. Ortalamaları esas alan indislerde rölatif değişimlerde genel olarak büyük hatalar türeten QM yöntemi, KPO indisine göre Gölmarmara, Avşar ve Üçpınar istasyonlarında daha küçük hata değerleri ile projeksiyonlar türetebilmiştir. DQM yöntemi ile ilgili indise göre sadece Muradiye istasyonunda en iyi sonuçlar elde edilebilmiştir. Aylık ekstrem yağışları temsil eden Y95 ve Y99 indislerinde ise ortalamaları esas alan indislere göre daha farklı sonuçlar elde edilmiştir. Y95 indisi ile elde edilen rölatif değişimler ve bunlara karşıllk gelen hata değerlerine göre, ERQM diğer yöntemlere göre performans açısından daha iyi sonuçlar türetebilmiştir. Bu indise göre QM ve DQM istasyonların 6'sında, QDM ise istasyonların 7'sinde rölatif değişimleri daha iyi yansıtarak yağışları modelleyebilmişlerdir. Y99 indisinde ise QM 39 istasyonun 21'inde QDM ise 11'inde daha iyi sonuçlar üretebilmişlerdir.

Söz konusu indisler için yapılan hesaplamalarda yine AO'da olduğu DQM ve ERQM yöntemleri istasyonların bir kısmında daha küçük mutlak hata değerleri türettiği 
gözlenmiştir. KPO indisinde ise yanlılık düzeltme yöntemlerinin performansları istasyonlara göre farklılık göstermektedir. Bu indise göre rölatif değişimlerin ERQM metodu ile 39 adet istasyonun 20'sinde diğer yöntemlere göre daha iyi modellenebildiği gözlenmiştir. Yine bu istasyonların 15'inde QDM metodu KPO indisine ait rölatif değişimleri daha iyi yansıttığı gözlenmiştir. Ortalamaları esas alan indislerde rölatif değişimlerde genel olarak büyük hatalar türeten QM yöntemi, KPO indisine göre Gölmarmara, Avşar ve Üçpınar istasyonlarında daha küçük hata değerleri ile projeksiyonlar türetebilmiştir. DQM yöntemi ile ilgili indise göre sadece Muradiye istasyonunda en iyi sonuçlar elde edilebilmiştir. Aylık ekstrem yağışları temsil eden Y95 ve Y99 indislerinde ise ortalamaları esas alan indislere göre daha farklı sonuçlar elde edilmiştir. Y95 indisi ile elde edilen rölatif değişimler ve bunlara karş1lık gelen hata değerlerine göre, ERQM diğer yöntemlere göre performans açısından daha iyi sonuçlar vermiştir. $\mathrm{Bu}$ indise göre $\mathrm{QM}$ ve DQM istasyonların 6'sında, QDM ise istasyonların 7'sinde rölatif değişimleri daha iyi yansıtarak yağışları modelleyebilmişlerdir. Y99 indisinde ise QM 39 istasyonun 21'inde QDM ise 11'inde daha iyi sonuçlar ortaya çıkmıştır.

A.

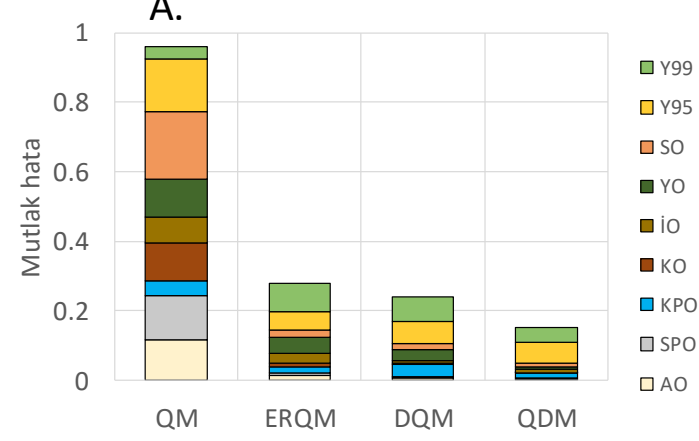

B.

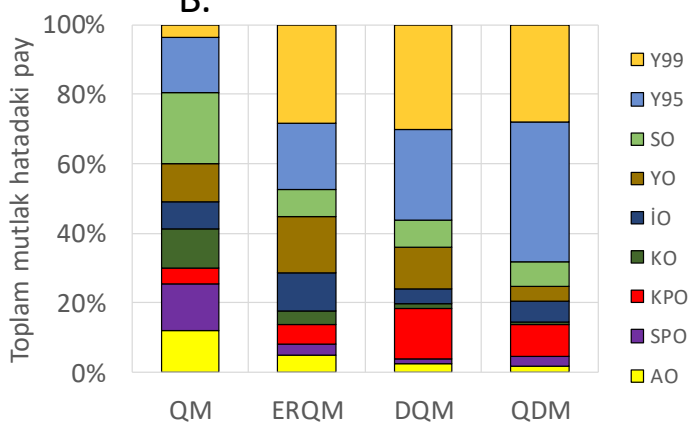

Şekil 3. Foça meteoroloji istasyonu için performans indislerine göre eklenik hataları ve bu hataların indislere göre paylarını gösteren eklenik çubuk diyagramı

Çalışmada kullanılan indislerdeki hataların toplamları kıyaslandığında tüm istasyonlarda, QM yönteminden elde edilmiş yağış projeksiyonlarındaki rölatif değişimlere ait hataların diğer yöntemlere göre daha büyük olduğu sonucuna varılmıştır. Kullanılan indislerce elde edilen toplam hatalarda en küçük değerler QDM yanlılık düzeltme yöntemi ile elde edilmiştir. Hatalardaki paylar göz önüne alındığında ERQM, DQM ve QDM yöntemlerinde en büyük hatalar ekstrem süreçleri temsil eden Y95 ve Y99 indislerinde gözlenmektedir. İlgili yöntemler toplam hatanın yaklaşık \%30'unu Y99 indisinde üretmektedir. QM yöntemi için ise Y99 indisine göre elde edilen hatalar QM yönteminin ürettiği toplam hatalar içerisinde en küçük paya sahiptir ( \%3). Genel olarak diğer yöntemlere göre daha iyi performans gösteren QDM yöntemi ise toplam hataların yaklaşık \%40'ını Y95 indisinde türetmiştir. QM metodu AO, SPO ve SO başta olmak üzere genel olarak ortalama değerlerine bağlı indislerde daha yüksek hata değeri türettiği gözlenmiş, bu üç indise göre ölçülen hatalar toplam hataların yaklaşık \%45'ini temsil etmektedir. Tüm indislerde ortaya çıkan hatalar ve bu hataların toplam hatalardaki payını gösteren eklenik sütun grafikleri Foça meteoroloji istasyonu için örnek olarak Şekil 3 'te verilmiştir. 


\section{Sonuçlar}

Yanlılık düzeltme yöntemleri kaba çözünürlük GCM'lerden gelen yanlılıkları düzeltmekte etkili bir araç olup iklim değişikliği çalışmalarının vazgeçilmez bir bileşeni haline gelmiştir. Literatürde farklı stratejileri esas alan yöntemler mevcut olup bu yöntemleri ile farklı projeksiyonlar elde edilebilmektedir. Yanlılık düzeltme yöntemleri gelecek dönem projeksiyonlarında düzeltilmemiş GCM'lerdeki rölatif değişimleri iyi yansitabilmeli ve bu hususta performansları değerlendirilebilmektedir. Bu çalışmada dağılım tabanlı 4 adet yanlılık düzeltme yönteminin performansı sınanmış ve tanımlanan farklı performans indislerine göre ilgili yöntemler birbirleri ile kıyaslanmıştır. Çalışma Gediz Havzası yağışları için uygulanmış ve IPCC'nin son değerlendirme raporunda belirtilen RCP senaryolarını esas alan 12 adet iklim modeli ile Gediz Havzası yağışları modellenmiştir. ANN ve LSSVM tabanlı istatistiksel ölçek indirgeme modelleri ile kaba çözünürlüklü GCM'ler referans ve RCP8.5 senaryolarına göre istasyon ölçeğine indirgenmiş daha sonra BMA yöntemi ile çoklu modeller ağırlıklandırılarak istatistiksel olarak belirsizliği azaltılmış projeksiyonlar türetilmiştir. PPCC testi ile 2 parametreli Gamma dağılıma uyduğu tespit edilen gözlenen, REF ve RCP8.5 senaryolarına ait Gediz Havzası yağışları, QM, ERQM, DQM ve QDM yöntemleri ile ayrı ayrı yanlılıkları düzeltilmiş ve uzun dönem ortalamaları ve ekstrem süreçleri değerlendiren 9 adet performans indisi ile sınanmıştır. Yapılan değerlendirmelere göre QDM yöntemi ortalama bazlı indislerin çoğunda rölatif değişimleri diğer yöntemlere göre daha küçük hatalarla simüle edebilmiştir. Bunların arasında kurak dönem ortalamalarını temsil eden KPO indisine göre ERQM yöntemi daha uygun sonuçlar vermiştir. Ekstrem süreçleri temsil 95. ve 99. yüzdelik değerlerinin toplamını temsil eden Y95 ve Y99 indislerine göre ortalamalara göre daha farklı sonuçlar elde edilmiştir. Y99 indisine göre QM diğer yöntemlere nazaran daha iyi performans göstermiştir. Y95 indisine göre ise ERQM yöntemi diğer yöntemlere göre rölatif değişimleri daha iyi yansıtmıştır. İndislerce elde edilen hataların toplamı göz önüne alındığında en küçük toplam hatalar QDM metodu, en büyük hatalar ise QM metodu ile elde edilmiştir. İlgili toplam hatalardaki indislerin payları incelendiğinde, diğer yöntemlere göre daha iyi performans gösteren QDM metodu hataların anlamlı bir bölümünü Y95 ve Y99 indislerinde üretmiştir (yaklaşık \%70). Bu durumda Gediz Havzası aylık toplam yağışları için QDM yöntemi ortalamalara ait değişimleri ekstrem süreçlere ait değişimlere göre daha iyi modelleyebildiği söylenebilir. Yöntemlerin farklı havzalara ve değişkenlere uygulanması ile alakalı çalışmalar tarafımızca sürdürülmektedir. Örnek olarak ele alınan Gediz Havzasının su kaynakları yönetimi için çoklu kriterli karar verme süreci modellemesi Yilmaz ve Harmancioglu [29, 30] tarafından gerçekleştirilen çalışmalarda daha önce ele alınmıştır. Gerek Okkan ve Kirdemir[3, 4] tarafından yürütülen çalışmalar, gerekse bu çalışma ile elde edilen yansız yağış projeksiyonları kullanılarak havzadaki akışların ve çok kriterli karar verme sürecinin ne ölçüde etkileneceği gelecek çalışmalarımızda ayrıca sorgulanacaktır.

\section{Teșekkür}

$\mathrm{Bu}$ çalışma, ikinci yazar tarafından yürütülen, Türkiye Bilimsel ve Teknolojik Araştırma Kurumu (TÜBİTAK)-Çevre, Atmosfer, Yer ve Deniz Bilimleri Araştırma Destek Grubu (ÇAYDAG) tarafından desteklenen 114Y716 numaralı tamamlanmış proje içeriğinden hazırlanmıştır. Yazarlar çalışmayı özenle değerlendiren iki hakeme ayrıca müteşekkirdir. 


\section{Kaynaklar}

[1] IPCC, Climate Change 2013 - The Physical Science Basis. Contribution of Working Group I to the Fifth Assessment Report of the Intergovernmental Panel on Climate Change, 1535, (2013).

[2] Ghosh, S. ve Mujumdar, P.P., Statistical downscaling of GCM simulations to streamflow using relevance vector machine, Advances in Water Resources, 31, 1, 132-146, (2008).

[3] Okkan, U. ve Kirdemir, U., Downscaling of monthly precipitation using CMIP5 climate models operated under RCPs, Meteorological Applications, 23, 3, (2016).

[4] Okkan, U. ve Kirdemir, U., Investigation of the Behavior of an AgriculturalOperated Dam Reservoir Under RCP Scenarios of AR5-IPCC, Water Resources Management, 32, 8, 2847-2866, (2018).

[5] Gudmundsson, L., Bremnes, J. B., Haugen J. E., ve Engen-Skaugen, T., Technical Note: Downscaling RCM precipitation to the station scale using statistical transformations-a comparison of methods, Hydrology and Earth System Sciences, 16, 9, 3383-3390, (2012).

[6] Lenderink, G., Buishand, A. ve Van Deursen, W., Estimates of future discharges of the river Rhine using two scenario methodologies: Direct versus delta approach, Hydrology and Earth System Sciences, 11, 3, 1145-1159, (2007).

[7] Leander, R. ve Buishand, T.A., Resampling of regional climate model output for the simulation of extreme river flows, Journal of Hydrology, 332, 3-4, 487496, (2007).

[8] Leander, R., Buishand, T.A., van den Hurk, B.J.J.M. ve de Wit, M.J.M, Estimated changes in flood quantiles of the river Meuse from resampling of regional climate model output, Journal of Hydrology, 351, 3-4, 331-343, (2008).

[9] Schmidli, J., Frei, C., ve Vidale, P.L., Downscaling from GCM precipitation: A benchmark for dynamical and statistical downscaling methods, International Journal of Climatology, 26, 5, 679-689, (2006).

[10] Ines, A.V.M. ve Hansen, J.W., Bias correction of daily GCM rainfall for crop simulation studies, Agricultural and Forest Meteorology, 138, 1-4, 44-53, (2006).

[11] Jakob Themeß1, M., Gobiet, A. ve Leuprecht, A., Empirical-statistical downscaling and error correction of daily precipitation from regional climate models, International Journal of Climatology, 31, 10, 1530-1544, (2011).

[12] Teutschbein, C. ve Seibert, J., Bias correction of regional climate model simulations for hydrological climate-change impact studies: Review and evaluation of different methods, Journal of Hydrology, 456-457, 12-29, (2012).

[13] Cannon, A.J., Sobie, S.R. ve Murdock, T.Q., Bias correction of GCM precipitation by quantile mapping: How well do methods preserve changes in quantiles and extremes?, Journal of Climate, 28, 17, 6938-6959, (2015).

[14] Chen, J., Brissette, F.P., Chaumont, D. ve Braun, M., Finding appropriate bias correction methods in downscaling precipitation for hydrologic impact studies over North America, Water Resources Research, 49, 7, 4187-4205, (2013).

[15] Fang, G.H., Yang, J., Chen, Y.N. ve Zammit, C., Comparing bias correction methods in downscaling meteorological variables for a hydrologic impact study in an arid area in China, Hydrology and Earth System Sciences, 19, 6, 2547- 
2559, (2015).

[16] Hempel, S., Frieler, K., Warszawski, L., Schewe, J. ve Piontek, F., A trendpreserving bias correction \&ndash; The ISI-MIP approach, Earth System Dynamics, 4, 2, 219-236, (2013).

[17] Block, P.J., Souza Filho, F.A., Sun, L. ve Kwon, H.H., A streamflow forecasting framework using multiple climate and hydrological models, Journal of the American Water Resources Association, 45, 4, 828-843, (2009).

[18] Boe, J., Terray, L., Habets, F. ve Martin, E., Statistical and dynamical downscaling of the Seine basin climate for hydro-meteorological studies, International Journal of Climatology, 27, 1643-1655, (2007).

[19] Sennikovs, J. ve Bethers, U., Statistical downscaling method of regional climate model results for hydrological modelling, 18th World IMACS/MODSIM Congress, 3962-3968, Cairns, Australia, (2009).

[20] Maraun, D., Bias Correction, Quantile Mapping, and Downscaling: Revisiting the Inflation Issue, Journal of Climate, 26, 2137-2143, (2013).

[21] Okkan, U. ve Inan, G., Statistical downscaling of monthly reservoir inflows for Kemer watershed in Turkey: Use of machine learning methods, multiple GCMs and emission scenarios, International Journal of Climatology, 35, 11, 32743295, (2015).

[22] Okkan, U. ve Inan, G., Bayesian Learning and Relevance Vector Machines Approach for Downscaling of Monthly Precipitation, Journal of Hydrologic Engineering, 20, 4, (2015).

[23] Kirdemir, U., İklim değişikliğinin baraj havzası hidrolojisi üzerindeki olası etkilerinin modellenmesi: AR5-RCP senaryoları ve Demirköprü Barajı örneği, Yüksek Lisans Tezi, Balıkesir Üniversitesi Fen Bilimleri Enstitüsü, Balıkesir, (2017).

[24] Moriasi, D.N., Arnold, J.G., Van Liew, M.W., Binger, R.L., Harmel, R.D. ve Veith, T.L., Model evaluation guidelines for systematic quantification of accuracy in watershed simulations, Transactions of the ASABE, 50, 3, 885900, (2007).

[25] Knutti, R. et al., Good Practice Guidance Paper on Assessing and Combining Multi Model Climate Projections, IPCC Expert Meeting on Assessing and Combining Multi Model Climate Projections, (2010).

[26] Wang, L. and Chen W., Equiratio cumulative distribution function matching as an improvement to the equidistant approach in bias correction of precipitation, Atmospheric Science Letters, 15, 1-6, (2014).

[27] Li, H., Sheffield J. ve Wood, E.F., Bias correction of monthly precipitation and temperature fields from Intergovernmental Panel on Climate Change AR4 models using equidistant quantile matching, Journal of Geophysical Research, 115, (2010).

[28] Olsson, J., Berggren, K., Olofsson, M. ve Viklander, M., Applying climate model precipitation scenarios for urban hydrological assessment: A case study in Kalmar City, Sweden, Atmospheric Research, 92, 3, 364-375, (2009).

[29] Yilmaz, B., ve Harmancioglu, N., Multi-criteria decision making for water resource management: a case study of the Gediz River Basin, Turkey, Water SA, 36, 5, 563-576, (2010).

[30] Yilmaz, B., ve Harmancioglu, N., An indicator based assessment for water resources management in Gediz River Basin, Turkey, Water Resources Management, 24, 15, 4359-4379, (2010). 